\title{
Racism and mental health among university students in Mexico City
}

\author{
Luis Ortiz-Hernández, PhD, (I) Ma Sandra Compeán-Dardón, MPH, (') \\ Elizabeth Verde-Flota, MA, ${ }^{(1)}$ Maricela Nanet Flores-Martínez, BSc. ${ }^{(1)}$
}

\section{Ortiz-Hernández L, Compeán-Dardón MS, Verde-Flota E, Flores-Martínez MN. Racism and mental health among university students in Mexico City. Salud Publica Mex 2011;53:125-133.}

\begin{abstract}
Objective. To assess whether differences exist in experiences of discrimination, perceptions of physical attractiveness, socioeconomic position, and mental health according to student's skin color. Materials and Methods. The population included students from a public university in Mexico City. The following three groups were created based on skin color: white, light brown, and brown. By means of regression models, we evaluated whether differences in mental health according to skin color could be due to experiences of discrimination, perceptions of physical attractiveness, and/or socioeconomic position. Results. Students with brown skin had lower levels of self-esteem and vitality and higher levels of fatigue and alcohol consumption. These differences were explained by more frequent experiences of discrimination and because students with brown skin perceived themselves as less attractive. Conclusions. This is one of the first studies to document the possible effects of racism on mental health among the urban population.Verification of these findings in representative samples is required.
\end{abstract}

Key words: racism, mental health, discrimination, self concept, beauty, Mexico
Ortiz-Hernández L, Compeán-Dardón MS,

Verde-Flota E, Flores-Martínez MN.

Racismo y salud mental en estudiantes

universitarios de la Ciudad de México.

Salud Publica Mex 201 I;53:125-133.

\section{Resumen}

Objetivos. Conocer si existen diferencias en experiencias de discriminación, percepción del atractivo físico, posición socioeconómica y salud mental en función del color de la piel. Material y métodos. La población consistió en estudiantes de una universidad de la Ciudad de México. A partir del color de piel se formaron tres grupos: blancos, morenos claros y morenos. Mediante modelos de regresión se evaluó si las diferencias en salud mental de acuerdo al color de piel se debían a experiencias de discriminación, percepción del atractivo físico y/o posición socioeconómica. Resultados. Los que tenían piel morena tuvieron niveles más bajos de autoestima y vitalidad, pero más altos de cansancio y de consumo de alcohol. Estas diferencias fueron explicadas por las experiencias de discriminación y porque los estudiantes morenos se percibían menos atractivos. Conclusiones. Por primera vez se documentan los posibles efectos del racismo en la salud mental en población urbana de México.

Palabras clave: racismo, salud mental, discriminación, autoestima, belleza, México

(I) Universidad Autónoma Metropolitana, Unidad Xochimilco, Mexico.

Received on: July 8, 2009 - Accepted on: February 3, 2011

Address reprint requests to: Dr. Luis Ortiz-Hernández. Universidad Autónoma Metropolitana. Calzada del Hueso II 00

Col. Villa Quietud, Coyoacán, México, D.F., México, 04960.

E-mail: lortiz@correo.xoc.uam.mx. 
$\mathrm{T}^{\mathrm{s}}$ he concept of race has been criticized ${ }^{1}$ because it makes reference to the existence of genetically homogenous groups that can be distinguished from one another; however, these groups do not exist, and this is especially true for the Latin American population. ${ }^{2}$ On the other hand, racism has been defined as institutional arrangements and/or individual beliefs, attitudes, and acts that tend to denigrate individuals or groups because of their phenotypic characteristics or their affiliation with an ethnic group. This is expressed as differences in the treatment of individuals and in their access to opportunities. $^{3-5}$

When racism is addressed, it is frequently used to describe the disadvantages of Blacks or people of African descent with respect to Caucasians or those of European descent. This observation is well-documented in industrialized countries. ${ }^{5}$ Recently, in Latin American countries such as Brazil, analyses have begun concerning the differences in morbidity and mortality between Black and Caucasian populations. ${ }^{6,7}$

In Latin America, the concept of ethnic groups has been key to understanding differences between indigenous populations (contemporary groups related to Mesoamerican groups) residing in rural areas and the Mestizo population inhabiting urban areas. ${ }^{8}$ While the majority of these studies has been focused on malnutrition- and infection-associated morbidity and mortality, mental health has been less frequently studied; in addition, said research has been done within a biomedical framework. ${ }^{9}$

A little analyzed observation in Mexico in particular, and in Latin America in general, is that there are skin color-related differences in treatment within the urban population. In a literature review concerning social inequality in health in Latin America, AlmeidaFilho et al. ${ }^{10}$ concluded that, with the exception of Brazil, there has been little exploration of the roles that racial and ethnic discrimination play in health and disease distribution. In the case of Mexico, while sociological and anthropological research studies have been carried out to document racism, there is currently no research concerning the association of this form of racism with health outcomes.

As in the majority of Latin American countries, racism in Mexico has its origin in the colony established by Spain. During the colonial era, a system of categories was developed to justify the economic exploitation of the native people. In this system, hierarchies were established that placed the Spanish population at the highest position and the Native Indian and Black populations at the lowest. It was argued that the natives were biologically and culturally inferior, and the politics of segregation were thus established. ${ }^{11,12}$ From that time forward, skin color was and is a mark that serves to confer differential treatment. These hierarchies were reproduced and reinforced through the formation of the Mexican nation. For example, during the 19th century in Mexico, the racist theories that were developing in Europe and the U.S. were very influential. Later, in addition to the hierarchy established between the Spaniards and the Indians, the distinction between American (Caucasian) versus Mexican (brown skin people, or moreno) was added. ${ }^{12}$

Stratification associated with skin color continues to occur in Mexico. ${ }^{13}$ Construction and reproduction of skin color-related stratification is based on divisions associated with the white-brown dichotomy: beautyugliness, intelligence-dullness, etcetera. ${ }^{12}$ Thus, there are nicknames that endow Indians (and therefore, the physical characters associated with them) with ignorance, clumsiness, lack of manners, and ugliness. Given that Caucasian features are associated symbolically with positive aspects, people then aspire to possess these characteristics.

One of the problems with studying racism in Mexico is that the forms of discrimination are not overt. ${ }^{13}$ For example, there are no eugenic groups that push for "racial purity." Nonetheless, this does not mean that racism does not exist, but rather that racism is expressed in veiled or subtle forms. For example, $43 \%$ of the Mexican population believes that the indigenous population will always possess social limitations due to their racial characteristics, and $34.1 \%$ expressed the opinion that the Indian, in order to emerge from poverty, would be required to avoid their "Indian behavior."14

Two explanations have been proposed to explain the relationship between racism and health outcomes: "racial minorities" are overrepresented at lower socioeconomic positions ${ }^{15}$ and they are more likely to experience discrimination. ${ }^{4}$ Another explanation for these differences lies in the stereotypes of beauty, in which white skin is associated with attractiveness. ${ }^{13}$ Therefore, subjects with brown skin perceive themselves as less physically attractive, which can cause greater psychological distress. ${ }^{16}$ In this case, these subjects have internalized the social norms that negatively evaluate some of their traits. ${ }^{17}$

The hypotheses proposed for the exploratory study reported herein include: 1) in comparison to students with white skin, those with brown skin would have higher levels of psychological distress, and 2) said differences in psychological distress could result in the latter subjects facing discriminatory experiences with greater frequency, belonging to lower socioeconomic strata, and/or perceiving that they do not meet the societal norms of beauty. 


\section{Materials and Methods}

A cross-sectional survey was carried-out. The studied population comprised students from the health professions (nursing, nutrition, medicine, and dentistry) at the National Metropolitan Autonomous University, who at the time of field work (November and December 2007) were studying in the $8^{\text {th }}, 9^{\text {th }}$, and $10^{\text {th }}$ trimesters. These three levels were selected because another of the survey objectives was to investigate harassment and discrimination experiences that the students had faced at the university. The response rates were $94 \%(\mathrm{~N}=122)$ in nursing, $87 \%(\mathrm{~N}=123)$ in nutrition, $72 \%(\mathrm{~N}=127)$ in medicine, and $84 \%(\mathrm{~N}=228)$ in dentistry.

The first page of the questionnaire included an explanation of the objectives of the study, in addition to the informed consent form. Only students who agreed to participate in the study were included. Prior to questionnaire implementation, several tests were conducted to verify that the questions were comprehensible. The ethical aspects of the study were approved by the Research Committee of the Division of Biological and Health Sciences of the Metropolitan Autonomous University.

Students were asked to assess the color of their skin according to nine response options, which included the following four groups: 1) white: 'very white or blond' and 'white'; 2) 'light brown'; 3) brown: 'brown that is neither light or dark' and 'dark brown'; and 4) other, including 'red-head,' 'black,' 'yellow,' and 'no option is adequate.'

The education of the primary wage-earner of the household was used to evaluate socioeconomic position, which was grouped into three categories: 1) low: secondary education or less; 2) middle: high school or technical course; and 3) high: undergraduate degree, equivalent or higher.

Experiences of discrimination were assessed by means of the application of ten questions, which have been validated in Spanish, concerning unfair treatment in daily life and two questions concerning major discrimination events. ${ }^{18,19}$ The complete original discrimination questionnaire ${ }^{18}$ was not applied because some of the investigated events (occupational discrimination or discrimination in obtaining a home) are not relevant for the majority of university students because they are economically dependent on their families. Each question had four response choices that were dichotomized as follows: 1) no: 'never', and 2) yes: 'once', 'two or three times' and 'four or more times.'

Exploratory factorial analyses of these questions were carried out (Table I). The first factor was denoted "experiences of mistreatment" and included seven

Table I

FACtORIAL ANALYSIS SCALE OF DISCRIMINATION EXPERIENCES*

\begin{tabular}{|c|c|c|c|c|c|c|}
\hline & \multicolumn{4}{|c|}{ Distribution of responses } & \multicolumn{2}{|c|}{ Factorial analysis } \\
\hline & $N$ & IT & $2-3 T$ & $\geq 4 T$ & & \\
\hline & $\%$ & $\%$ & $\%$ & $\%$ & $\mathrm{FI}$ & $F 2$ \\
\hline Eigen value & & & & & 4.30 & 1.14 \\
\hline Percentage of variant & & & & & 35.8 & 9.5 \\
\hline I.You have been treated with less courtesy than other people & 35.1 & 29.1 & 27.5 & 8.3 & 0.78 & 0.14 \\
\hline 2. You have been treated with less respect than other people & 49.7 & 23.7 & 22.2 & 4.4 & 0.77 & 0.16 \\
\hline 3.You have received poorer service than other people at restaurants or stores & 56.0 & 20.9 & 19.0 & 4.2 & 0.54 & 0.28 \\
\hline 4. People have acted as if they think you are not smart & 50.2 & 24.7 & 20.0 & 5.1 & 0.69 & 0.12 \\
\hline 5. People have acted as if they are afraid of you & 64.3 & 17.5 & 13.3 & 4.9 & 0.27 & 0.56 \\
\hline 6. People have acted as if they think you are dishonest & 74.0 & 16.0 & 7.8 & 2.3 & 0.37 & 0.52 \\
\hline 7. People have acted as if they're better than you are & 26.0 & 23.0 & 35.8 & 15.3 & 0.69 & 0.17 \\
\hline 8. You have been called nicknames or insulted & 47.3 & 26.5 & 19.1 & 7.0 & 0.58 & 0.24 \\
\hline 9. You have been threatened or harassed & 58.3 & 23.9 & 13.1 & 4.7 & 0.42 & 0.36 \\
\hline 10.You have been followed around in stores & 74.2 & 14.0 & 7.6 & 4.2 & 0.18 & 0.64 \\
\hline $\begin{array}{l}\text { II. Have you ever been unfairly stopped, searched, questioned, physically threatened or } \\
\text { abused by the police? }\end{array}$ & 85.3 & 9.8 & 3.0 & 1.9 & 0.00 & 0.80 \\
\hline $\begin{array}{l}\text { 12. Have you ever been unfairly discouraged by a teacher or advisor from continuing } \\
\text { your education? }\end{array}$ & 75.0 & 19 & 3.4 & 2.7 & 0.34 & 0.22 \\
\hline
\end{tabular}

* Data from a questionnaire given to students from a public university in Mexico City, November-December 2007.Abbreviations: N, never; IT, one time; 2-3T, two to three times; $\geq 4 \mathrm{~T}$, four or more times 
questions. Three groups were formed according to the number of experiences: none, 1-3, and 4-7. The second factor was termed "experiences of harassment" and included five questions. Three groups were formed according to the number of experiences, as follows: none, $1-2$, and 3-5.

Study participants were asked how they perceived themselves in terms of physical attractiveness, in comparison with other people. There were five response options pertaining to this question, for which the following three groups were created: 1) less attractive: 'much less attractive than most people,' and 'a little less attractive than most people'; 2) the same level of attractiveness: 'as attractive as most people,' and 3) more attractive: 'a little more attractive than other people' and 'much more attractive than the majority of people.'

Mental health was evaluated by means of the Rosenberg self-esteem scale validated for adolescents in Mexico City. ${ }^{20}$ This scale included ten items with four response options ranging from 'full agreement' to 'full disagreement,' which were scored from one to four. The scores of all 10 items were summed. To assess psychological distress, the mental health-related items from Health Survey SF-36 were applied..$^{21}$ The response options for the items were scored on a scale of zero to five. Factorial analysis was performed on the responses and two factors were identified. The first factor was denominated vitality and included the questions: 'Have you felt full of life?' ‘Have you felt so down that nothing can cheer you up?' ‘Have you felt quiet and calm?' ‘Have you had a lot of energy?' 'Have you felt discouraged and sad?' 'Have you felt happy?' Of these questions, those worded in a negative sense were given inverse scores and the scores of all six questions were added. The second factor was termed fatigue and included the following questions: 'Have you felt tired?' ‘Have you felt worn out?' 'Have you felt very nervous?' The scores of these three items were added together. Alcohol consumption was evaluated with three items from the Alcohol Use Disorder Identification Test (AUDIT):22 'How often do you consume beverages containing alcohol?' 'In general, how many beverages (drinks) that contain alcohol do you drink?' 'How often do you consume six or more drinks on the same occasion?' Response options were assigned scores from zero to four and summed. This resulted in an alcohol consumption index in which the highest values indicated the greatest consumption.

The descriptive statistics of studied variables were estimated (Table II). Chi-squared and analysis tests were used to determine whether there were statistical differences according to skin color (Table III). Analysis of variance was used to compare mental health indicators according to socioeconomic position, discriminatory
Table II

SOCIO-DEMOGRAPHIC CHARACTERISTICS of StUdents at A UniVersity IN MeXico City (November-December, 2007)

$\begin{array}{lll}\text { Variables } & N & \%\end{array}$

Degree course

\begin{tabular}{lrc} 
Nursing & 115 & 21.7 \\
\hline Dentistry & 218 & 41.1 \\
\hline Medicine & 88 & 16.6 \\
\hline Nutrition & 109 & 20.6
\end{tabular}

Skin color

\begin{tabular}{lcc} 
White & 121 & 23.0 \\
\hline Light brown & 212 & 40.2 \\
\hline Brown & 182 & 34.5 \\
\hline Other & 13 & 2.5
\end{tabular}

Gender

\begin{tabular}{lll} 
Men & 144 & 27.3 \\
\hline Women & 384 & 72.7
\end{tabular}

Socioeconomic position

\begin{tabular}{lll} 
Low & 163 & 31.6 \\
\hline Middle & 134 & 26.0 \\
\hline High & 219 & 42.4
\end{tabular}

Experiences of mistreatment ( $n$ )

\begin{tabular}{lrl}
0 & 77 & 14.8 \\
\hline $1-3$ & 143 & 27.5 \\
\hline $4-7$ & 300 & 57.7
\end{tabular}

Experiences of harassment ( $n$ )

\begin{tabular}{lrc}
0 & 185 & 35.7 \\
\hline $1-2$ & 239 & 46.1 \\
\hline $3-5$ & 94 & 18.1
\end{tabular}

Perception of attractiveness

\begin{tabular}{lcc} 
Less attractive & 63 & 12.1 \\
\hline Same level of attractiveness & 306 & 58.7 \\
\hline More attractive & 152 & 29.2 \\
\hline & Mean & $\begin{array}{c}\text { Standard } \\
\text { deviation }\end{array}$ \\
\hline Age & 23.4 & 3.9 \\
\hline Self-esteem & 33.8 & 4.4 \\
\hline Vitality & 20.7 & 5.2 \\
\hline Fatigue & 6.8 & 2.6 \\
\hline Alcohol consumption & 2.7 & 2.5
\end{tabular}


Table III

DIFFERENCES IN SOCIOECONOMIC POSITION, EXPERIENCES OF DISCRIMINATION, AND PERCEPTION OF BEAUTY AND MENTAL HEALTH ACCORDING TO SKIN COLOR*

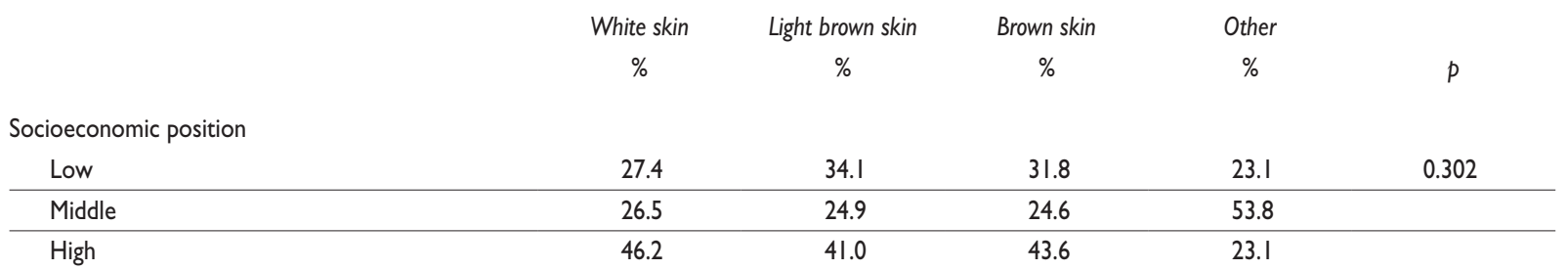

Experiences of mistreatment $(n)$

\begin{tabular}{|c|c|c|c|c|c|}
\hline 0 & 11.7 & I7.I & 14.5 & 15.4 & 0.025 \\
\hline $1-3$ & 40.0 & 22.9 & 23.5 & 38.5 & \\
\hline $4-7$ & 48.3 & 60.0 & 62.0 & 46.2 & \\
\hline
\end{tabular}

Experiences of harassment $(n)$

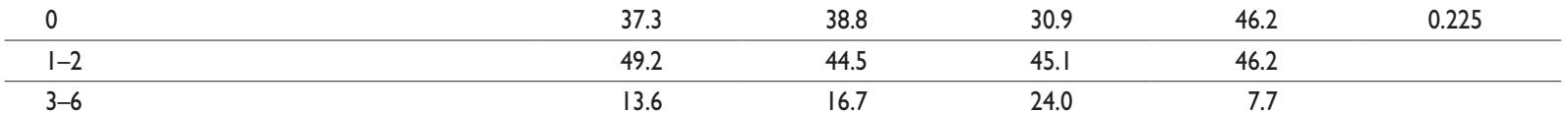

Perception of attractiveness

\begin{tabular}{|c|c|c|c|c|c|}
\hline Less attractive & 4.2 & 12.0 & 17.3 & 8.3 & 0.005 \\
\hline Same level of attractiveness & 56.3 & 59.6 & 60.3 & 50.0 & \\
\hline \multirow[t]{2}{*}{ More attractive } & 39.5 & 28.4 & 22.3 & 41.7 & \\
\hline & $M$ & $M$ & $M$ & $M$ & \\
\hline Self-esteem & 34.5 & 33.8 & 33.3 & 33.8 & 0.163 \\
\hline Vitality & 21.5 & 20.6 & 20.2 & 21.0 & 0.248 \\
\hline Fatigue & 6.5 & 6.7 & 7.3 & 7.2 & 0.025 \\
\hline Alcohol consumption & 2.6 & 2.4 & 3.0 & 3.1 & 0.122 \\
\hline
\end{tabular}

* Data from a questionnaire given to students from a public university in Mexico City, November-December 2007.Abbreviation: M, mean

experiences, and perception of physical attractiveness (Table IV). Linear regression models were estimated to evaluate whether the variables mentioned above mediated the association between skin color and mental health. ${ }^{23}$ In these models, the group "other" defined according to skin color was excluded because, in addition to being the minority $(n=13)$, the categories included ("yellow" or "reddish") were not of interest for the proposed hypotheses. In model A, the effect of skin color on each mental health indicator was assessed; in model $\mathrm{B}$, in addition to skin color, socioeconomic position was incorporated; in model $\mathrm{C}$, skin color and mistreatment experiences were added; in model D, skin color and harassment experiences were added, and; in model E, skin color and perception of physical attractiveness were included. Models B to E were estimated to ascertain whether the effect of skin color on mental health remained when other mediators were incorpo- rated. In all models, age and gender were included as confounders.

\section{Results}

The most frequent form of discrimination (Table I) was that some people had acted in a superior manner to the surveyed students $(74.1 \%$ responded that having occurred at least one time during his/her life). This was followed by students who had been treated less courteously than others, those who had been insulted or who had been called a nickname that they did not like, and those who had been treated with less respect than others. The majority of the study population was composed of dentistry students, persons with light brown skin, females, persons with a high socioeconomic position, and those who perceived themselves to be as attractive as other people (Table II). Addition- 
Table IV

DifFERENCES IN MENTAL HEALTH INDICATORS ACCORDING TO SOCIOECONOMIC POSITION, EXPERIENCES OF DISCRIMINATION, AND PERCEPTION OF BEAUTY*

\begin{tabular}{lcccc} 
& \multicolumn{5}{c}{ Socioeconomic position } \\
\cline { 2 - 5 } & Low & Middle & High \\
Self-esteem & $M$ & $M$ & $M$ & $p$ \\
\hline Vitality & 33.4 & 33.7 & 34.1 & 0.303 \\
\hline Psychological distress & 19.7 & 20.9 & 21.4 & 0.006 \\
\hline Alcohol consumption & 7.3 & 7.1 & 6.4 & 0.004 \\
\hline
\end{tabular}

\begin{tabular}{lrrrc} 
& \multicolumn{5}{c}{ Experiences of mistreatment $(\mathrm{n})$} \\
\cline { 2 - 5 } & 0 & $1-3$ & $4-7$ & \\
Self-esteem & $M$ & $M$ & $M$ & $p$ \\
\hline Vitality & 36.5 & 34.6 & 32.8 & 0.000 \\
\hline Fatigue & 23.4 & 21.6 & 19.6 & 0.000 \\
\hline Alcohol consumption & 5.8 & 6.5 & 7.3 & 0.000 \\
\hline
\end{tabular}

\begin{tabular}{lcccc} 
& \multicolumn{5}{c}{ Experiences of harassment $(n)$} \\
\cline { 2 - 5 } & 0 & $1-2$ & $3-6$ & \\
Self-esteem & $M$ & $M$ & $M$ & $p$ \\
\hline Vitality & 34.6 & 33.4 & 33.1 & 0.005 \\
\hline Psychological distress & 21.9 & 20.0 & 20.0 & 0.001 \\
\hline Alcohol consumption & 6.2 & 7.2 & 7.5 & 0.000 \\
\hline
\end{tabular}

\begin{tabular}{lcccc} 
& \multicolumn{4}{c}{ Perception of attractiveness } \\
\cline { 2 - 5 } & $\begin{array}{l}\text { Less } \\
\text { attractive }\end{array}$ & Average & More \\
& $M$ & $M$ & $M$ & $p$ \\
Seltractive & \\
Self-esteem & 29.3 & 34.4 & 34.4 & 0.000 \\
\hline Vitality & 17.1 & 21.0 & 21.5 & 0.000 \\
\hline Psychological distress & 7.6 & 6.7 & 6.8 & 0.040 \\
\hline Alcohol consumption & 2.5 & 2.5 & 3.0 & 0.141
\end{tabular}

* Data from a questionnaire given to students from a public university in Mexico City, November-December 2007.Abbreviation: M, mean

ally, $57.7 \%$ of students had experienced 4-7 forms of mistreatment, and $46.1 \%$ had experienced one or two forms of harassment.

The proportion of students with brown skin who had experienced mistreatment or perceived themselves as less attractive was greater; in addition, they had higher levels of fatigue than those with white skin (Table III).

In comparison to students from the high socioeconomic stratum, those with low socioeconomic position possessed lower levels of vitality and reported less alcohol consumption, but had higher levels of fatigue
(Table IV). Compared to the students who had not experienced mistreatment, those who had experienced mistreatment reported lower levels of self-esteem and vitality and higher levels of fatigue. Students who reported experiences of harassment had less self-esteem and vitality, and higher levels of fatigue and alcohol consumption. With respect to students who perceived themselves as attractive, those not perceiving themselves as attractive presented lower self-esteem and vitality and higher fatigue.

In regression models (Table V), students with brown skin had lower levels of self-esteem in comparison with students who had white skin; these differences were maintained after adjusting for socioeconomic position and harassment experiences, but disappeared when the experiences of mistreatment or perceptions of physical attractiveness were added. Students with brown skin color also reported lower levels of vitality; this pattern was not modified after adjusting for socioeconomic position or harassment experiences, but disappeared when the mistreatment experiences or perception of physical attractiveness were added. Students with brown skin presented higher levels of fatigue, a situation maintained after adjusting for socioeconomic position, mistreatment experiences, harassment experiences, or perceptions of physical attractiveness. Upon adjusting for age and gender, alcohol consumption was not different among the three skin color groups $(\beta=0.22 ; p=$ $0.122)$; thus, we did not estimate models adjusted by mediator variables.

\section{Discussion}

The findings of this study complement those of researchers in the field of social sciences ${ }^{11-13}$ with respect to the existence in Mexico of skin color-related discriminatory practices, given that students with brown skin had a greater probability of experiencing discrimination. This pattern could be attributed to the Eurocentric vision that predominates in Mexico. Similarly, beauty is a social construct, in that its definition varies according to time and place, ${ }^{16}$ thus, differences in self-perception of how attractive students were in terms of skin color can be interpreted as the acceptance of social norms, in which white skin is equivalent to beauty and brown skin is evaluated in negative terms.

According to the bibliographic review, this is the first study in Mexico that documents that people with brown skin present a poorer mental health state than subjects with white skin. These differences cannot be attributed to biological differences, ${ }^{2}$ but rather, skin color-associated health inequalities can be the result of social processes that exert negative effects on disadvan- 
Table V

REGRESSION MODELS WITH MENTAL HEALTH INDICATORS AS DEPENDENT VARIABLES*

\begin{tabular}{|c|c|c|c|c|c|c|}
\hline & \multicolumn{2}{|c|}{ Self-esteem } & \multicolumn{2}{|c|}{ Vitality } & \multicolumn{2}{|c|}{ Fatigue } \\
\hline & $\beta$ & $p$ & $\beta$ & $p$ & $\beta$ & $p$ \\
\hline \multicolumn{7}{|l|}{ Model A } \\
\hline Skin color & -0.59 & 0.025 & -0.68 & 0.029 & 0.43 & 0.004 \\
\hline \multicolumn{7}{|l|}{ Model B } \\
\hline Skin color & -0.62 & 0.021 & -0.66 & 0.033 & 0.42 & 0.006 \\
\hline Socioeconomic position & 0.35 & 0.137 & 0.73 & 0.009 & -0.37 & 0.007 \\
\hline \multicolumn{7}{|l|}{ Model C } \\
\hline Skin color & -0.44 & 0.088 & -0.56 & 0.063 & 0.38 & 0.010 \\
\hline Experiences of mistreatment & -1.81 & 0.000 & -2.02 & 0.000 & 0.80 & 0.000 \\
\hline \multicolumn{7}{|l|}{ Model D } \\
\hline Skin color & -0.55 & 0.038 & -0.68 & 0.028 & 0.42 & 0.005 \\
\hline Experiences of harassment & -0.94 & 0.001 & -1.46 & 0.000 & 0.71 & 0.000 \\
\hline \multicolumn{7}{|l|}{ Model E } \\
\hline Skin color & -0.37 & 0.155 & -0.44 & 0.156 & 0.39 & 0.011 \\
\hline Perception of physical attractiveness & 1.80 & 0.000 & 1.77 & 0.000 & -0.30 & 0.115 \\
\hline
\end{tabular}

taged groups. If this is the case in Mexico (and perhaps in other Latin American countries), it is worthwhile to study racism as another social determinant of health, similar to other aspects such as socioeconomic position and gender.

Considering the proposed hypothesis, a mediator ${ }^{23}$ should fulfill certain characteristics, such as being most frequently in the disadvantaged group, associated with the health outcomes studied, and its incorporation into regression models should result in a decrease in estimations of association between exposure (skin color) and outcomes (mental health indicators). Three mediators (perceptions of physical attractiveness, experiences of discrimination, and socioeconomic position) were postulated for explaining differences in health among skin color groups. Regarding the first mediator, we obtained the following results: students with brown skin most frequently perceived themselves as less attractive; students who perceived themselves as less attractive had lower levels of self-esteem and vitality and higher fatigue levels, and; perceptions of physical attractiveness explained the relationship of skin color with self-esteem and vitality. These results can provide evidence of the psychological distress that results when possessing an attribute that is socially evaluated as negative, which can be experienced as a chronic stressor that is lived and reinforced daily. Until now, ${ }^{3}$ the individual's perception of attractiveness had not been considered as a possible mediator between health and the inequities that derive from racism.

One indicator of discrimination was more common among students with brown skin. Additionally, as mistreatment experiences increased, their levels of self-esteem and vitality decreased, and higher levels of fatigue were present. Finally, experiences of mistreatment explained the association of skin color with selfesteem and vitality. In recent years, the negative effect exerted by discrimination on mental health has been consistently documented. ${ }^{5,24}$ Among the mechanisms postulated as an explanation for this effect is the fact that discriminatory acts create and reinforce negative self-concept in the people affected because they have a characteristic that is negatively evaluated. ${ }^{25} \mathrm{~A}$ prior experience of discrimination on one occasion can result in 
perceiving or anticipating future acts of discrimination, which in turn creates feelings of fear, anxiety, and anger that can eventually be as a chronic stressor, accompanied by psychological consequences. ${ }^{3,26}$

In industrialized countries, there is a wide range of evidence that the differences in health status between Caucasian and Black populations are, to a great extent, due to socioeconomic disparities, which can imply, among other aspects, working in jobs with less control or living in geographic areas with fewer opportunities for maintaining a healthy lifestyle. ${ }^{15,27}$ Nevertheless, among students in Mexico City, there are no skin color-associated socioeconomic differences; additionally, socioeconomic position did not explain any of the differences in mental health indicators. This is possibly due to a selection bias, because the research was carried out with university students. In Mexico, less than $4 \%$ of the adult population achieves a university level education, principally due to socioeconomic factors. Thus, it cannot be underestimated that people with brown skin have a greater probability of belonging to low economic strata, ${ }^{11}$ and therefore have fewer possibilities of reaching upper academic levels. If this occurs, the results of the present study would be biased toward null values; therefore, the differences in experiences of discrimination and mental health indicators among individuals with different skin color would have been underestimated. Future studies that utilize representative samples from a wide geographic zone to encompass the socioeconomic disparities that characterize Mexican society are warranted.

Among the limitations of this study is the assessment of skin color. First, certain skin color-related terms ("fair" or "olive" skin - piel apiñonada o trigueña) are ambiguous or possess a distinct meaning for different people. Second, when people are asked to report the color of their skin, they compare it with the color of the skin of other people; thus, people living among individuals whose skin is darker tend to report themselves as having lighter skin, while the opposite occurs when an individual resides among people with lighter skin. This problem can bias estimations toward null values. However, in the research of "racial" and ethnic inequities, the evaluation of skin color or ethnic identification based on the report of subjects has been a common practice. ${ }^{28,29}$

Another limitation is that measurement of the variables was based on information reported by the students. Report-based measures can lead to people with psychological distress reporting discriminatory events with greater frequency due to their psychological state; nevertheless, prior evidence shows that this does not occur. ${ }^{5}$ Education level was used as a proxy variable of socioeconomic position. While such a variable could be an inadequate indicator of family wealth because there is not a perfect correlation among education, occupation and income, it is recognized as an indicator of social capital.

Although we did not obtain a random sample of all students from health professions, we believe that our results adequately reflect the situation of this population because: 1) Although the differential participation according to experiences of discrimination was not studied, in the case that any bias exists the effect would be minimal due to the relatively high response rate $(>70 \%)$. 2) Although we only surveyed students in three courses out of the twelve, the sample is considered to be valid since the studied population is socially and demographically similar across the generations. ${ }^{30} 3$ ) The age and sex composition of students of different career courses from the public university where the study was carried out is similar to those of students at other educational institutions ${ }^{31}$ and of practicing health professionals at the national level. ${ }^{32}$

In summary, in this study, we observed that students with brown skin had lower self-esteem and vitality levels and higher levels of fatigue than students with white skin. These differences were not explained by socioeconomic position, but rather by experiences of discrimination and because students with brown skin perceived themselves as being less attractive. Documenting the existence of differences in experiences of discrimination and health problems in terms of skin color is a first step toward making the existence of racism visible in Mexican society.

Because of the exploratory nature of this study, it is necessary to verify whether the results obtained herein are confirmed in representative samples from different age groups. If these results are replicated in other samples, then it would be worthwhile to consider the incorporation of questions concerning skin color in national surveys and censuses, because this could serve for monitoring social and health inequalities associated with racism. In addition, institutions and policies directed toward combating discrimination need to broaden their attention not only to include ethnic discrimination toward Indigenous populations but also to include other expressions of racism, because the latter is a factor that has been underestimated. One theme to explore in the future is the possible existence of spatial segregation $^{33,34}$ according to skin color and its association with health outcomes. Ethnographic research ${ }^{11}$ suggests that in Mexico, segregation exists among people of high socioeconomic strata (among which people with white skin predominate) and that of low strata (among 
which people of brown skin predominate). Likewise, the existence of other forms of discrimination (by social class, sexual orientation or physical attractiveness) and their effects on health must be the objective of future analyses.

Declaration of conflicts of interest: The authors declare that they have no conflict of interests.

\section{References}

I. Stolley PD. Race in epidemiology. Int J Health Services I999; 29(4): 905-909.

2. Tishkoff SA, Kidd KK. Implications of biogeography of human populations for 'race' and medicine. Nature Genetics 2004; 36(II):S2I-S27.

3. Clark R,Anderson NB, Clark VR, Williams DR. Racism as a stressor for African Americans. Am Psychol 1999; 54(10):805-816.

4. Krieger N. Does racism harm health? Did child abuse exist before 1962? On explicit questions, critical science, and current controversies:An ecosocial perspective. Am J Public Health 2003; 93(2): 194- 199.

5. Williams DR, Neighbors HW, Jackson JS. Racial/ethnic discrimination and health: Findings from community studies. Am J Public Health 2003; 93(2):200-208.

6. Chor D, Lima CR. Epidemiologic aspects of racial inequalities in health in Brazil. Cad Saude Publica 2005; 2 I (5): I586-I594.

7. Barata RB, de Almeida MF, Montero CV, da Silva ZP. Health inequalities based on ethnicity in individuals aged 15 to 64, Brazil, 1998. Cad Saude Publica 2007; 23(2):305-3I3.

8. Montenegro RA, Stephens C. Indigenous health 2 - Indigenous health in Latin America and the Caribbean. Lancet 2006; 367(9525): I859-I869.

9. Sebastian MS, Hurtig AK. Review of health research on indigenous populations in Latin America, 1995-2004. Salud Publica Mex 2007; 49(4):316-320.

10. Almeida-Filho N, Kawachi I, Pellegrini A, Dachs JNW. Research on health inequalities in Latin America and the Caribbean: Bibliometric analysis (1971-2000. and descriptive content analysis (I97|-1995).Am J Public Health 2003; 93( I 2):2037-2043.

I I. Nutini HG. Class and ethnicity in Mexico: Somatic and racial considerations. Ethnology 1997; 36(3):227.

12. Castellanos Guerrero A. Exclusión étnica en ciudades del centro y sureste. Mexico City: Dirección General de Equidad y Desarrollo Social, Gobierno del Distrito Federal, 2005. 12-6-2007.

13. Moreno Figueroa MG. Historically-rooted transnationalism: slightedness and the experience of racism in mexican families.J Intercultural Stud 2008; 29(3):283-297.

14. CONAPRED - SEDESOL. Primera Encuesta Nacional sobre Discriminación en México. 2005. Mexico City: Consejo Nacional para Prevenir la Discriminación; Secretaría de Desarrollo Social. I5. Williams DR. Race/ethnicity and socioeconomic status: Measurement and methodological issues. Int J Health Services 1996; 26(3):483-505. 16. Cash TF.The psychology of physical appearance: aesthetics, attributes, and images. In: Cash T, Pruzinsky T, editors. Body images: development deviance and change. New York: Guildford, 1990: 51-79.
17. Stuber J, Meyer I, Link B. Stigma, prejudice, discrimination and health. Soc Sci Med 2008; 67(3):35I-357.

18. Williams DR, Yu Y, Jackson NB,Anderson NB. Racial differences in physical and mental health: Socio-economic status, stress and discrimination.J Health Psychol 1997; 2:335-35I.

19. Krieger N, Smith K, Naishadham D, Hartman C, Barbeau EM. Experiences of discrimination:Validity and reliability of a self-report measure for population health research on racism and health. Soc Sci \& Med 2005; 61 (7): I576-I596.

20. González-Forteza C,Andrade P, Jiménez A. Recursos psicológicos relacionados con el estrés cotidiano en una muestra de adolescentes mexicanos. Salud Mental 1997; 20(I):27-35

21. Zuniga MA, Carrillo-Jimenez GT, Fos PJ, Gandek B, Medina-Moreno MR. Health status evaluation with the SF-36 survey: Preliminary results in Mexico. Salud Publica Mex 1999; 4 I (2): I I0-I I8.

22. Medina-Mora E, Carreño S, de la Fuente J. Experiences with Alcohol Use Disorders Identification Test (AUDIT. in Mexico. In: Galanter, M, editors. Alcoholism. New York:American Society of Addiction Medicine and Research Society on Alcoholism, 1998: 383-395.

23. Baron RM, Kenny DA. The Moderator Mediator Variable Distinction in Social Psychological-Research - Conceptual, Strategic, and Statistical Considerations. J Personality Soc Psychol 1986; 5 I (6): I I73-I I82.

24. Kessler RC, Mickelson KD,Williams DR. The prevalence, distribution, and mental health correlates of perceived discrimination in the United States. J Health Soc Behav 1999; 40(3):208-230.

25. Ortiz-Hernandez L, Garcia Torres MI. Effects of violence and discrimination on the mental health of bisexuals, lesbians, and gays in Mexico City. Cad Saude Publica 2005; 2 I(3):913-925.

26. Harrell JP, Hall S, Taliaferro J. Physiological responses to racism and discrimination:An assessment of the evidence.Am J Public Health 2003; 93(2):243-248.

27. Sudano J], Baker DW. Explaining US racial/ethnic disparities in health declines and mortality in late middle age:The roles of socioeconomic status, health behaviors, and health insurance. Soc Sci Med 2006; 62(4):909-922.

28. Nobles M. History counts:A comparative analysis of racial/color categorization in US and Brazilian censuses. Am J Public Health 2000; $90(I \mid): 1738-1745$.

29. Amaro H, Zambrana RE. Criollo, mestizo, mulato, LatiNegro, indigena, white, or black? The Hispanic/Latino population and multiple responses in the 2000 census. Am J Public Health 2000; 90(II): I724-I727.

30. Gallardo-Hernandez G, Ortiz-Hernandez L, Compean-Dardon S, Verde-Flota E, Delgado-Sanchez G, Tamez-Gonzalez S. Intersection between gender and socioeconomic status in medical sciences career choice. Gac Med Mex 2006; I42(6):467-476.

31. Asociación Nacional de Universidades e Instituciones de Educación Superior. Estadísticas de la Educación Superior.Asociación Nacional de Universidades e Instituciones de Educación Superior, 2005. 5-9-2008. 32. Ramírez MA, Méndez O, Nigenda G,Vargas MM. Recursos humanos en los servicios de salud: una perspectiva de género. Mexico: Centro de Análisis Social y Económico, Fundación Mexicana para la Salud, 2002. 33. David R,Williams PM, Chiquita Collins P. Racial Residential Segregation: A Fundamental Cause of Racial Disparities in Health. Public Health Rep 200I; II6:404-4I6.

34. Acevedo-Garcia D, Lochner KA, Osypuk TL, Subramanian SV. Future directions in residential segregation and health research:A multilevel approach.Am J Public Health 2003; 93(2):2I5-22I. 